\title{
O discurso de ódio e a liberdade de expressão: seu feito sobre a dignidade humana e apotencialização da violênci
} Hate speech and freedom of expression: its effect on human dignity and the violence potentialization

El discurso de odio y la libertad de expresión: su efecto sobre la dignidad humana y la potencialización de la violencia

Vanessa Bittencourt Santana ${ }^{1}$ Pedro Pereira Borges ${ }^{2}$

${ }^{1}$ Graduanda em Direito pela Universidade Católica Dom Bosco (UCDB), Campo Grande, Mato Grosso do Sul. Pesquisadora bolsista de iniciação científica pela UCDB. E-mail: v.3.bittencourt@gmail.com, ORCID: https://orcid.org/0000-0002-9638-8999

${ }^{2}$ Doutor e mestre em Ciências Sociais pela Pontifícia Universidade Católica de São Paulo (PUC-SP). Graduado em Pedagogia pela Universidade Católica Dom Bosco (UCDB); em Teologia, pelo Instituto Santo Tomás de Aquino; e em Filosofia, pelas Faculdades Unidas Católicas de Mato Grosso (FUCMT). Professor no Programa de Pós-Graduação Mestrado e Doutorado em Desenvolvimento Local da UCDB. E-mail: pobojari@ucdb.br, ORCID: http://orcid.org/0000-0001-9183-5051 
Resumo: O presente artigo traz uma análise sobre a manifestação do Discurso do Ódio instaurado na sociedade com exteriorização de ideias discriminatórias direcionadas a determinados grupos minoritários, considerando o discurso como um problema social pilar da violência e que afeta princípios como a liberdade de expressão e a dignidade humana. 0 objetivo foi demonstrar as diferenças entre o discurso de ódio e a liberdade de expressão, como o ódio afeta, direta e indiretamente, o aumento de violência e indicar maneiras que auxiliam o combate. Para tanto, a metodologia utilizada foi a revisão bibliográfica de artigos científicos, notícias e leis que versam sobre o tema. O resultado auferido é que a educação, os direitos e um maior zelo nas redes sociais e na mídia jornalística são capazes de diminuir o alcance do discurso de ódio, a fim de instaurar uma transformação social em consonância com os preceitos da Constituição Federal.

Palavras-chave: discurso de ódio; liberdade de expressão; violência.

\begin{abstract}
This article analyzes the manifestation of the Hate Speech established in society with the expression of discriminatory ideas directed at certain minority groups, considering it as a social problem that is a pillar of violence and that affects principles such as freedom of expression and dignity human. The objective was to demonstrate the differences between hate speech and freedom of expression, how hate, directly and indirectly, affects the increase in violence and to indicate ways that help combat it. For that, the methodology used was the bibliographic review of scientific articles, news and laws that deal with the theme. The result obtained is that education, rights and a greater zeal in social networks and in the journalistic media are capable of reducing the scope of hate speech in order to establish a social transformation in line with the precepts of the Federal Constitution.
\end{abstract}

Keywords: hate speech; freedom of expression; violence.

Resumen: Este artículo analiza la manifestación del Discurso de Odio establecido en la sociedad con la expresión de ideas discriminatorias dirigidas a ciertos grupos minoritarios, considerándolo como un problema social que es pilar de la violencia y afecta principios como la libertad de expresión y la dignidad. humano. El objetivo fue demostrar las diferencias entre el discurso de odio y la libertad de expresión, cómo el odio afecta, directa e indirectamente, el aumento de la violencia e indicar formas que ayuden a combatirlo. Para ello, la metodología utilizada fue la revisión bibliográfica de artículos científicos, noticias y leyes que abordan el tema. El resultado obtenido es que la educación, los derechos y un mayor celo en las redes sociales y en los medios periodísticos son capaces de reducir el alcance del discurso de odio con el fin de establecer una transformación social acorde con los preceptos de la Constitución Federal.

Palabras clave: discurso del odio; libertad de expresión; violencia. 
O discurso de ódio e a liberdade de expressão: seu feito sobre a dignidade humana e apotencialização da violência

\section{INTRODUÇÃO}

O mundo das ideias, dentre suas variantes, tem características positivas e negativas. Algumas destas não são capazes de existir dentro de um convívio social do mundo fático sem que haja algum dano. O discurso de ódio, fundado na discriminação de minorias por meio da disseminação e da exteriorização de ideias preconceituosas, é causador de ameaça social, acabando por desrespeitar direitos e princípios fundamentais que sustentam o convívio social, como a dignidade humana, posto que a liberdade de expressão consegue mascará-lo.

O discurso de ódio se torna, portanto, um problema social que resvala no direito, na psicologia, na sociologia e em outras dimensões da vida humana. Isso por si atrai o foco de atenção do legislador, do pesquisador e das autoridades como um todo para o tema. Debater sobre o discurso de ódio passa a ser imprescindível, tanto pelo Estado quanto pelas instituições de educação, que agregam valores a grupos de pessoas que se tornam formadores de opiniões.

O presente trabalho tem como objetivos 1) verificar como o discurso de ódio possui a capacidade de aumentar a violência, 2) distinguir discurso de ódio de liberdade de expressão, 3) analisar os modos como o discurso de ódio se propaga na sociedade e 4) investigar sobre as formas de combate ao discurso de ódio.

A metodologia aplicada foi a revisão bibliográfica, que serviu de base para a construção do trabalho. Os dados foram coletados entre leis e doutrinas, em projetos de lei em tramitação no Congresso Nacional, na Constituição Federal quanto à liberdade de expressão e ao direito de resposta, entre autores que discorrem sobre o tema de modo geral, como Hannah Arendt e John Stuart Mill. Trata-se de um tema atual. Portanto também foi feito um mapeamento de notícias sobre o tema, entre o ano de 2019 e o primeiro trimestre de 2020.

$\mathrm{O}$ artigo foi dividido em seis tópicos. No primeiro, analisa-se como a liberdade de expressão se distingue do discurso de ódio, partindo da Constituição Federal de 1988. O segundo tópico aborda como o discurso de ódio influencia na violência de forma direta e indireta. O tópico seguinte 
aborda sobre como o discurso de ódio está impregnado na sociedade, sendo gerador de conflitos de diversas montas. O quarto tópico aborda sobre como a internet se tornou um ambiente facilitador da propagação do discurso de ódio e de conteúdos capazes de promover e incentivar discriminações. No quinto tópico, é feita uma abordagem sobre o discurso de ódio em tempos de pandemia do novo coronavírus, como a doença tem proporcionado a geração de discriminações corroborada pela desinformação. Por fim, o último tópico apresenta o direito de resposta como uma das formas de combate ao discurso de ódio e uma breve análise de como têm sido as decisões dos tribunais quanto ao tema.

\section{AS MUDANÇAS SOCIAIS E O CONFLITO DE PRINCÍPIOS}

O Brasil vem passando por transformações, mudanças e por uma reconstrução de cenários que chegaram para ficar. As transformações pelas quais passa o país acabam gerando também uma massa de "opiniões", muitas vezes sem rosto ou endereço, mas com voz e um apego nunca antes visto à liberdade de expressão, que acaba gerando e, ao mesmo tempo, ocultando o chamado discurso de ódio.

As mudanças mencionadas são decorrentes de diversos fatores. Um deles é de que há atualmente uma maior participação das minorias na sociedade. Elas buscam garantir os direitos que Ihes foram outorgados, entre os quais, o polimorfismo dos novos arranjos familiares que fogem ao tradicional perpetuado por séculos, o reconhecimento da mulher como chefe de família e sua crescente presença no mercado de trabalho e, principalmente, a internet, que se consolidou como a maior rede de comunicação e de informação, tornando-se um mercado de oportunidades. Em contrapartida, seu crescimento avassalador nas últimas décadas não veio acompanhado das devidas medidas de segurança, passando assim a ser entendida por muitos como "terra de ninguém". Isso faz com que ela se torne um ambiente propício ao discurso do ódio.

Apesar de bater tantas vezes na tecla do novo, isso não é algo recente. A sua maneira de expressar é que se renovou. Atualmente, há muitas maneiras de publicização do discurso de ódio. Entre elas, as redes sociais 
O discurso de ódio e a liberdade de expressão: seu feito sobre a dignidade humana e apotencialização da violência

ampliam o alcance das falas dos seus perpetradores e ainda são capazes de modificar ou revelar o verdadeiro contexto do que foi dito. Isso pode ir diametralmente contra o projeto de criação de uma sociedade brasileira igualitária, como prescreve a Constituição Federal de 1988.

O discurso de ódio vem de encontro com a liberdade de expressão e a sua disseminação coloca essa liberdade em cheque. A liberdade, mais uma vez, tem de enfrentar o fato de que nenhum direito pode ser desvirtuado ou transgredido e que a subjetividade em relação aos direitos garante o desenvolvimento, amplia os horizontes e, ao mesmo tempo, faz uma moldura baseada em pensar quantas vezes for preciso, quando, como e de modo inovador, se é necessário dizer algo em determinadas circunstâncias.

A sociedade brasileira tem a sua característica fundada na diversidade cultural, de costumes, de religiões, capazes de criar uma cultura chamada de brasileira. Abordar essa diversidade é importante e necessário para começar a pensar sobre como e por que as coisas acontecem do jeito que acontecem e saem dos limites do como deveria acontecer.

A expressão "como deveria acontecer", aparentemente, é utópica, mas a partir dela pode-se analisar e compreender o que se espera de uma sociedade mais justa e igualitária, de acordo com os princípios estabelecidos pela Constituição Federal de 1988. Diante disso, tornou-se indispensável a ação legislativa no sentido de limitar e regrar as condutas sociais que fogem ao interesse coletivo. A verdade é que não se pode cercear o agir de alguém, salvo através da lei. Assim, convém enxergar o mundo como ele é, admitir que determinado problema existe e agir em prol do "como deveria ser".

O Art. 220, da Constituição Federal de 1988, prevê o livre pensamento e, ao final do caput, o dispositivo deixa claro que essa liberdade deve ser de acordo com os preceitos gerais da própria Constituição: "A manifestação do pensamento, a criação, a expressão e a informação, sob qualquer forma, processo ou veículo, não sofrerão qualquer restrição, observado o disposto nesta Constituição".

Desta forma, pode ser citado o Art. 5ํ, Inciso XLLV, que prevê o racismo como crime inafiançável e imprescritível, e também o Art. 3ํㅜ que contém os objetivos da Constituição Federal de 1988, que frisam o incentivo do bem coletivo frente ao individual: "Constituem objetivos fundamentais da República 
Federativa do Brasil: IV - Promover o bem de todos, sem preconceitos de origem, raça, sexo, cor, idade e quaisquer outras formas de discriminação".

Esses artigos mostram como a própria Constituição brasileira preceitua a liberdade plena, mas que o bem coletivo limita o direito, de forma justa e igualitária. O que está por trás disso é que a Constituição Federal de 1988 veda o anonimato da comunicação social em relação a grupos, pessoas e instituições e prevê a indenização por danos morais e materiais. Dessa forma, os vetores de qualquer discurso de ódio não podem buscar salvaguardas no texto constitucional, uma vez que este define a harmonia e a dignidade humana como necessárias para se exigir o direito à liberdade de expressão. Isto quer dizer que a harmonia social não se baseia na sobreposição do direito de liberdade de expressão que pode ser gerador do discurso de ódio.

O direito à liberdade é revolucionário. É uma das garantias fundamentais que foi e ainda está sendo inserida de forma progressiva na sociedade brasileira. Trata-se, porém, de uma construção atemporal e mutável. Silva (2005, p. 232) afirma que

Já delineamos que a liberdade tem um caráter histórico, porque "depende do poder o homem sobre a natureza, a sociedade, e sobre si mesmo em cada momento histórico". Realmente, a história mostra que o conteúdo da liberdade se amplia com a evolução da humanidade. Fortalece-se, estende-se, à medida que a atividade humana se alarga. Liberdade é conquista constante.

Desse modo, a liberdade precisa ser vista como algo inerente a cada indivíduo. Isso quer dizer que a escolha, a opinião, a crença, a roupa, o que o outro faz ou não com a liberdade dele não deveriam ser postos em discussão, salvo quando essa liberdade agride a dignidade de outrem. O discurso de ódio, portanto, não faz parte do direito à liberdade de expressão. Entende-se que a da liberdade só acaba quando há um dano, presente ou futuro. Segundo Adams e Dyson (2006, p. 117), "Ninguém - seja um indivíduo ou um governo - tem o direito de restringir a palavra, a publicação de ideias ou a conduta de alguém, a não ser para evitar que esse alguém cause danos a outra pessoa".

A liberdade de expressão, por tantos anos suprimida, tem um inimigo, potente e desafiador, sobre o qual se pode fazer analogia com a música 
O discurso de ódio e a liberdade de expressão: seu feito sobre a dignidade humana e apotencialização da violência

O bêbado e a equilibrista, de João Bosco e Aldir Blanc, interpretada por Elis Regina. Essa música, de 1979, marcou o renascimento da democracia no Brasil, nos versos que dizem: "Mas sei que uma dor assim pungente não há de ser inutilmente, a esperança, dança na corda bamba de sombrinha e em cada passo dessa linha pode se machucar".

A corda bamba é uma linha que não pode ser ultrapassada. De um lado, está o discurso de ódio e, do outro, o da liberdade de expressão. Quem dança deve saber que os passos precisam ser dados com mais cautela para que haja de fato a esperança de uma sociedade menos segregatícia. O equilibrista é um papel dado à sociedade e ao Estado capazes de enxergar e inibir as oscilações.

Não se pode deixar de dizer que o tema é intersubjetivo, que a diferença é tênue, mas de forte impacto. Corroborado com a crescente chuva de informações da atualidade, fica ainda mais difícil de ser compreendido de forma concreta.

A liberdade de expressão e a dignidade humana são os principais princípios afetados com o discurso de ódio. Isso os torna conflitantes. Expressar uma ideia preconceituosa com a intenção de agredir a dignidade ou integridade de alguém e ainda ter um respaldo na liberdade de expressão, isso não é uma validação de direitos, mas de abuso, assim expressam Costa e Freitas (2017): "Ser livre numa sociedade democrática é conseguir enxergar o outro; não o tornar invisível aos próprios olhos; é ser visto pelo seu interlocutor". Assegurar uma distinção entre o discurso de ódio e a liberdade de expressão é primordial para que não haja conflito entre os princípios.

\section{DISCURSO DE ÓDIO: A FORMA BASILAR DA VIOLÊNCIA}

O discurso de ódio se renova e se molda de acordo com a cultura e os costumes de cada sociedade, mas um ponto em comum entre todas é que esse tipo de discurso é e sempre foi utilizado como uma primeira fase da violência. Bugger (2007, p. 118) conceitua o que é conhecido como hate speech:

De acordo com a maioria das definições, o discurso do ódio refere-se a palavras que tendem a insultar, intimidar ou assediar pessoas em 
virtude de sua raça, cor, etnicidade, nacionalidade, sexo ou religião, ou que têm a capacidade de instigar violência, ódio ou discriminação contra tais pessoas.

O discurso de ódio é a expressão ou as formas de expressão de um grupo ou de um indivíduo que considera o outro como inferior étnica, social, religiosa ou moralmente, entre outras formas. Esse sentimento de superioridade pode desencadear a chamada desumanização de quem sofre os ataques de ódio. Isso faz com que pessoas que seguem o mesmo pensamento defendam e apliquem os mesmos princípios, levando a causar um impacto muito maior do que um único indivíduo que descrimina outro.

Assim sendo, trabalha-se a ideia de que é fácil odiar. O ódio une as pessoas e as ações e as reações humanas podem ser as mais diversas possíveis. Karnal (2017, p. 50) trabalha esse fundamento, afirmando que

O debate é longo, mas não há dúvida: as palavras ferem, não são inocentes. Elas deveriam ser controladas especialmente as politicamente incorretas, porque costumam trazer uma imprecisão. 0 politicamente incorreto traduz o preconceito e o preconceito entre outras características é falso. Tenta estabelecer uma generalização.

Tudo acontece como se fosse uma ciranda. Um homem que agride fisicamente a sua mulher muito provavelmente já a agrediu verbalmente inúmeras vezes. É como se a violência fosse feita por fases. Em uma entrevista para a ONU News (2019), Adama Dieng, conselheiro especial da Organização das Nações Unidas para prevenção de genocídios, explica que "[...] o holocausto não começou com as câmaras de gás, mas, muito antes, com discurso de ódio".

Essa volta ao passado serve para analisar mais profundamente o tema, quando se pensa nas repressões, nas guerras, na violência e nos genocídios que a humanidade já enfrentou por motivo de raça, sexo, religião ou etnia. Com isso, é possível lembrar os números, as tragédias e o que aconteceu no fim. Daí a importância de apontar alguns números.

As pessoas matam por ódio, pelo time de futebol, por briga no trânsito, por ciúme ou pelo som alto do vizinho, entre outras razões. No ano de 2012, foi lançada uma campanha intitulada conte até 10, pelo Conselho Nacional de Justiça e pelo Ministério da Justiça. A campanha foi iniciada após o alto 
O discurso de ódio e a liberdade de expressão: seu feito sobre a dignidade humana e apotencialização da violência

índice de homicídios por motivos fúteis, que, segundo estudos da época, só em São Paulo, 83\% dos homicídios foram classificados como cometidos por impulso e por motivo fútil.

A pergunta que fica é sobre o quanto a discriminação pode abarcar o crescimento deste índice. Segundo o atlas da violência do IPEA, até o ano de 2017, a desigualdade de raça/cor nas mortes violentas havia aumentado, com 75,5\% das vítimas de homicídios sendo pretas ou pardas no Brasil.

Não há uma comparação. Esses dados representam uma desestrutura, que, por sua vez, corresponde a um fato. O discurso de ódio por si só é uma forma de violar o direito de outros, mas também de potencializar outras formas de violência. Em um país em que o maior número de mortes é de negros e em um país em que mais se mata por motivo fútil, subalternizá-los com o discurso de ódio é no mínimo um estímulo.

\section{A RAIZ DA DISCRIMINAÇÃO DIANTE DA DEMOCRACIA E DOS DIREITOS HUMANOS}

As pessoas que engendram, pregam ou disseminam o ódio não têm um perfil específico. Tudo começa com o apontar das atitudes ruins sempre para o outro. Mas o fundamental é a análise no núcleo no qual cada indivíduo está inserido e se, de alguma forma, esse faz com que ele seja um disseminador de falas e ações discriminatórias.

No ano de 1961, Hannah Arendt acompanhou o julgamento de Adolf Eichmann, considerado um dos maiores organizadores do holocausto. A condenação era certa, mas o que se destaca desta história é a interpretação da autora, que coloca o mal como sendo algo banal. Arendt (1999, p. 299) expõe que, apesar de os crimes cometidos por ele e pelos nazistas serem um dos piores vivenciados pela humanidade, Eichmann era um homem comum:

Ele não era um monstro. Ao contrário, era um homem comum. E o mais assustador: tão comum quanto muitos outros. "O problema de Eichmann era exatamente que muitos eram como ele, e muitos não eram nem pervertidos, nem sádicos, mas eram e ainda são terrível e assustadoramente normais".

Em sua defesa, Eichmann dizia que apenas seguia ordens, que se considerava inocente. Isso traz um dos principais aspectos de debate desta 
pesquisa, de que, quando a pessoa se encontra inserida em determinado núcleo social, afetivo ou não, pode estar sujeita a adquirir e a seguir o que Ihe é colocado como atitudes aceitáveis e corretas.

O problema começa quando esses eixos são usados apenas para a satisfação de si próprio, com o sentimento de superioridade e não do coletivo. Esses comportamentos podem ser variados. Mas quando alguém, por exemplo, expressa uma fala racista acreditando estar correto, expõe o fato de esse eixo estar se sobrepondo não só a outro indivíduo, como também ao sistema social e legal como um todo.

A educação é história, é a análise de erros do passado com o intuito de que certas atitudes não voltem a ocorrer. Os princípios, os costumes, a liberdade e a igualdade são uma construção. Quanto mais núcleos como esses aparecerem e se sobressaírem ao sistema educacional, mais em crise um Estado estará.

Mas isso não implica uma intervenção do Estado no mundo das ideias. Se assim fosse, seria impossível defender a liberdade de expressão e de pensamento e deixar o Estado escolher valores que possam ou não serem pautados. O certo seria promover uma educação que tenha entre os seus objetivos informar e formar para que os indivíduos possam ter a autonomia de decidir de maneira não discriminatória, de enxergar o injusto e a subalternização do outro e reprimi-la naturalmente (MEYER-PFLUG, 2018).

Carneiro (2011) assegura que a democracia depende da dignidade humana e que não deve ser limitada apenas ao respeito aos direitos humanos, mas também repudiar a discriminação, respeitando as relações interpessoais. Então, o combate ao discurso de ódio não é referente a somente não o praticar, mas também afrontar aos que os fazem, inibi-los.

Carneiro (2019) afirma que "O discurso de ódio surge nas fissuras da democracia". Atualmente, o discurso de ódio abarca tanto os grupos minoritários (o ser diferente) quanto os grupos que não seguem as mesmas diretivas (o pensar diferente). Na verdade, já não é possível dizer: se você não pensa como eu, não serve; se não estiver comigo, estará contra mim, radical, totalitário injusto e antidemocrático.

Ideias políticas diversas fomentaram o aumento de ódio do pensar e do ser diferente. Entre o diálogo e uma construção social, o ódio aparentemente 
O discurso de ódio e a liberdade de expressão: seu feito sobre a dignidade humana e apotencialização da violência

sai ganhando. A polarização de grupos se tornou clara e efetivamente um movimento segregatício e de falta de informação. Para que essas ideias possam coabitar e justamente resgatar a plena democracia em que o povo possa se expressar sem tornar isso uma agressão à oposição, Santos (2003, p. 53) é do parecer de que

Temos o direito a ser iguais quando a nossa diferença nos inferioriza; e temos o direito a ser diferentes quando a nossa igualdade nos descaracteriza. Daí a necessidade de uma igualdade que reconheça as diferenças e de uma diferença que não produza, alimente ou reproduza as desigualdades.

Embora a raiz, isto é, a geração do ódio, possa ser identificada seja em sua forma estrutural na história e na cultura, seja no próprio individuo, é impossível dizer que haja também um fim, mas é importante destacar suas ferramentas, suas adequações do mundo contemporâneo.

\section{INTERNET: PRINCIPAL AMBIENTE DE TRANSMISSÃO}

A internet e as mídias sociais fazem parte de uma nova estrutura de comunicação social, com inúmeras funções, aplicativos, sites e todo tipo de interação entre os usuários, uma imensidão capaz de atingir todos a todo instante. A característica da imediaticidade presente no ambiente virtual, corroborada pelo possível uso do anonimato, traz uma grande potência para propagação do discurso de ódio. No mundo inteiro, isso teve muito impacto. Não é difícil ler comentários carregados de preconceito e discriminação gratuita presente em qualquer rede social.

Há medidas sendo tomadas, instituições que realizam o combate à discriminação exclusivamente na internet, como a SaferNet Brasil (2005), associação civil de direito privado que adota um perfil explicativo e acolhedor. Essa organização não governamental, que recebe denúncias e promove ações com cunho informativo sobre crimes cibernéticos, como o racismo, a homofobia, o neonazismo e a pornografia infantil, entre outros temas, ainda promove campanhas como a do Setembro Amarelo.

O site ainda informa que 2.263.060 foi o número de denúncias relacionadas a crimes de ódio recebidas pela SaferNet Brasil desde 2006, dados estes computados até o ano de 2019 . O racismo corresponde a 28\% entre 
as denúncias de crimes de ódio e 68\% das vítimas que procuram ajuda no Helpline são mulheres. O instituto mostra um aumento exponencial, que remete não necessariamente ao aumento da discriminação, mas também à conscientização dos usuários ao realizar a denúncia.

Há o Projeto de Lei n. 80, de 2016, em tramitação no Senado Federal, que pretende alterar o texto da Lei n. 7.716, de 5 de janeiro de 1989, a qual define os crimes resultantes de preconceito raça ou cor.

Art. 20. $\S 2$ o Se qualquer dos crimes previstos no caput for cometido por intermédio dos meios de comunicação social, de publicação de qualquer natureza, da internet ou de qualquer outra rede de computadores destinada ao acesso público: Pena: reclusão de dois a cinco anos e multa.

§ 30 III - a interdição das respectivas mensagens ou páginas de informação na rede Internet ou outra rede de computadores destinada ao acesso público.

Projeto de mudança nas leis como esse, com um texto minucioso e que ampara as mudanças sociais de forma concreta, é de suma importância para dar um possível início de soluções ao emaranhado de complexidade que o tema traz. Mas se percebe a falta de uma lei de imprensa, que dê um discernimento na forma de comunicação. As fakes news levam a discursos discriminatórios, as matérias sensacionalistas desestabilizam todo um viés digno de uma notícia sobre crimes.

Não há como falar da internet sem mencionar as fakes news. Elas entram no tema especialmente por trazerem manchetes inverossímeis, exageradas e que tendem a atacar e a gerar ataques. Elas também invadiram o cotidiano da população e as campanhas políticas, gerando uma Comissão Parlamentar de Inquérito (CPI), criada em setembro de 2019. Essa Comissão das Fake News, segundo o senador Ângelo Coronel, presidente da CPI, também focará em investigar as fake news geradas na pandemia do coronavírus. Esse tipo de investigação é fundamental por si só. Anterior aos resultados, o tema será debatido e estudado pelo Poder Legislativo, um ponto forte para que o tema deixe de ser tão categórico.

Existe também um projeto de lei que busca tipificar a divulgação das fake news, apresentado pelo senador Ciro Nogueira. A mudança no Código 
O discurso de ódio e a liberdade de expressão: seu feito sobre a dignidade humana e apotencialização da violência

Penal prevê detenção relacionada às situações como "[...] informações relacionadas à saúde, à segurança pública, à economia nacional, ao processo eleitoral ou que afetem interesse público relevante". Como já mencionado, o ódio une as pessoas. Quanto mais houver compartilhamentos de notícias que tendem a ser ruins e atacar mais pessoas, tanto mais vão se agrupar e gerar comentários preconceituosos.

\section{O AUMENTO DA DISCRIMINAÇÃO EM TEMPOS DE PANDEMIA E O PAPEL DA MÍDIA}

A cidade Wuhan, situada na China, marcou a origem do novo coronavírus, que posteriormente se tornou uma pandemia mundial. O desconhecimento do vírus não somente causou o descontrole do próprio, que se espalhou pelo mundo, mas também a acentuação do racismo e da xenofobia advindos da ignorância quanto ao contágio da doença e de suas peculiaridades.

O vírus é novo e ainda com muitos fatores desconhecidos, mas o racismo social que ele gera é antigo, se se fizer menção a outras doenças que causaram mortes em massa e foram um marco na história mundial, como a "peste negra", que aos judeus foi imputada no século XIX, tuberculose (pobres e negros), ebola (negros) e a aids (peste gay), entre tantas outras doenças epidêmicas e pandêmicas, as quais criam um vínculo do preconceito injusto já existente na sociedade, que é aflorado, tornando o momento ainda mais insociável.

Assim como o discurso de ódio, a doença é sempre do outro, é estranha, estrangeira, de outro mundo. O que difere de nós não deveria ser importante até que atingisse alguém da própria família, e a reação é de medo, insegurança, generalização e discriminação.

Os brasileiros descendentes de asiáticos relatam desde olhares a comentários xenofóbicos em locais públicos e na internet. Notícias e vídeos ganharam destaque a partir do Carnaval 2020, que definitivamente é o encontro da diversidade brasileira e anterior ao primeiro caso de infectados no país. Resta afirmar que a discriminação foi motivada apenas na ignorância e xenofobia. 
Depois de esses relatos se tornarem recorrentes em todas as partes do mundo, foi iniciado um protesto no qual as pessoas com descendência asiática levantaram a hashtag "\#eunãosouumvirús". Segundo o jornal El País, essa ação se deu após manchetes francesas se iniciarem com tons sugestivos, como Alerte jaune (alerta amarelo), seguido de Le péril jaune? (O perigo amarelo?).

O secretário-geral da ONU, António Guterres, emitiu um alerta no que chamou de "tsunami de ódio e xenofobia". Ele pediu apoio das mídias e das instituições educacionais para se dedicarem à alfabetização digital, posto que neste momento o aumento do uso da rede aumentou de forma significativa.

A mídia, que tem como papel fundamental, por um lado, levar a informação ao número máximo de pessoas, por outro lado, colabora de maneira tendenciosa para gerar comportamentos e criar estereótipos em relação às doenças que nada têm a ver a raça. Segundo Oliva (2005, p. 112),

No Ocidente, a televisão, com seu noticiário centrado no eixo Nova York- Londres- Paris- Tóquio, apenas abre espaço para a África para divulgar suas misérias e epidemias. [...]. Porém de uma forma geral, nos jornais impressos essa realidade se repete. Tornam-se elementos comuns no imaginário elaborado sobre a África, as imagens de sociedades "tribais" em conflito permanente; cidades desorganizadas e sujas; natureza selvagem e incontrolável; padrões culturais ritualizados e folclorizados; doenças misteriosas e temidas - como o vírus ebola.

A vinculação da mídia de forma alguma deve ser limitada e focada ao sensacionalismo ou às fake news. A mídia adota posições distintas. Por um lado, pode agredir, desinformar e gerar o caos. Por outro lado, desvincula-se do ódio e se torna capaz de defender a alteridade. Quando acontece essa segunda posição, a mídia, o jornalismo, é sinônima de democracia.

Não fugindo ao tema, é importante destacar que a busca pela qualidade da mídia como um instrumento capaz de gerar ideias positivas na sociedade de modo geral passa a ser tão importante quanto a educação básica. Torna-se claro que o envolvimento da mídia com interesses particulares volta e meia se sobressai, mas é um outro fator de mudança que deve prosperar. Segundo Mill (1991, p. 158), 
Um Estado que amesquinha os seus homens, afim de que sejam instrumentos mais dóceis nas suas mãos, ainda que para propósitos benéficos - descobrirá que com homens pequenos nada grande se pode fazer realmente; e que a perfeição do maquinário a que sacrificou tudo, não lhe aproveitará, no fim, nada, por carência da força vital que, para a máquina poder trabalhar mais suavemente, ele preferiu proscrever.

Posta essa assertiva, pode se concluir que a mídia de qualidade, não importando o meio, se jornais, revistas, televisão ou internet, é uma força necessária para criação de ideias e opiniões certas ou não, mas que tenham embasamento de um fato verdadeiro, e é capaz de gerar menos desgastes em momento vulneráveis e inesperados, como ocorre durante a pandemia, em que "os homens", como afirma Mill, devem possuir um papel mais agregador e essencial, inclusive para auxiliar nesses momentos uma melhor administração do Estado e tornar a liberdade de expressão como um direito mais consciente.

\section{DIREITO DE RESPOSTA E DECISÕES DOS TRIBUNAIS EM CASOS CONCRETOS}

Os grupos minoritários são os principais interessados na liberdade mutável, dita anteriormente, pois eles ainda continuam em busca dos seus direitos e, quanto mais direito, mais liberdade. Esse momento de conscientização e luta que parte de grupos indígenas, negros, mulheres, homossexuais e judeus é uma forma satisfatória de agregar e manter a liberdade de expressão em seu caráter mais concreto no mundo fático. Essas minorias não são pautas necessariamente pelo conjunto numérico, mas sim pela desigualdade da sua inserção social em relação aos demais, que pode ser definida como a segunda espécie de desigualdade pautada por Rousseau (2005, p. 31):

Concebo na espécie humana duas espécies de desigualdade: uma, que chamo de natural ou física, porque é estabelecida pela natureza, e que consiste na diferença das idades, da saúde, das forças do corpo e das qualidades do espírito, ou da alma; a outra, que se pode chamar de desigualdade moral ou política, porque depende de uma espécie 
de convenção, e que é estabelecida ou, pelo menos, autorizada pelo consentimento dos homens. Consiste esta nos diferentes privilégios de que gozam alguns com prejuízo dos outros, como ser mais ricos, mais honrados, mais poderosos do que os outros, ou mesmo fazerem-se obedecer por eles.

Desta maneira, uma desigualdade criada pelo próprio homem poderá ser combatida pelo próprio homem, buscando equidade no poder de fala, de voz, de ser ouvido, pois se há, de um lado, a liberdade de expressão, de outro, há também o direito de resposta, preceituado no Art. 5ㅇ, Inciso V, da Constituição Federal de 1988: "É assegurado o direito de resposta, proporcional ao agravo, além da indenização por dano material, moral ou à imagem".

A conscientização é tanto daqueles que buscam seus direitos quanto para quem quer uma sociedade melhor. As minorias vivem de acordo com as decisões a elas impostas. Pode-se dizer que eles apenas respondem às expressões daqueles que realmente possuem a liberdade de dizê-las. Para que se possa ajudar o outro, que é diferente quanto à cultura, à religião, à economia e ao status social, é preciso entendê-lo, conhecer e se pautar nos problemas por eles vividos.

O direito de resposta se torna uma forma de frear o discurso de ódio. É uma força necessária, um dinamismo, uma natural resistência. De acordo com Duarte e Dantas (2019), é um meio capaz de impulsionar a cidadania e a democracia. Embora o direito de resposta possa vir mediante ações judiciais com finalidade de indenizações, no Brasil as decisões que abarcam o tema não possuem um seguimento jurisprudencial, uma base mais consolidada. Tem-se decidido com base em cada caso concreto.

Há uma decisão do ano de 2018 do Tribunal Regional Federal da 4ạ região, em que o réu foi denunciado por mensagens antissemitas em uma rede social. O tribunal entendeu pela condenação do acusado, especificando o dolo:

Dessa forma, comprovada que a mensagem postada possui o dolo específico, por alguns denominado de discurso de ódio (hate speech), que foge da razoabilidade, colidindo com os princípios constitucionais já expostos como a igualdade e dignidade e o objetivo da promoção do bem de todos sem preconceito, bem como do direito à vida, 
O discurso de ódio e a liberdade de expressão: seu feito sobre a dignidade humana e apotencialização da violência

constituindo delito conforme ilustra o julgado do STF do HC 82.424/ RS, acima mencionado. Assim, não há que se cogitar o direito à liberdade de expressão, conforme quer fazer crer a defesa (BRASIL, 2018).

Já em outra ação, esta motivada pela intolerância religiosa, julgada pelo Supremo Tribunal Federal, o colegiado entendeu que, apesar do cunho preconceituoso, o acusado tinha respaldo na liberdade de expressão. Segundo o ministro relator, Edson Fachin (Brasil, 2016),

Sendo assim, a afirmação de superioridade direcionada à realização de um suposto resgate ou salvação, apesar de indiscutivelmente preconceituosa, intolerante, pedante e prepotente, encontra guarida na liberdade de expressão religiosa, e não preenche o âmbito proibitivo da norma.

Portanto, mediante análise, há um poder de criminalização ao discurso de ódio, à severidade e ao dolo da exposição das ideias. As decisões acima tendem a ser a principal forma de análise do Judiciário, mas há medidas que podem ser implementadas. Um entendimento mais consolidado também é importante para uma definição mais clara baseada nas leis específicas, princípios e costumes. Isso é importante para tornar o tema menos incerto e preservar a plena liberdade de expressão no sistema jurídico. Segundo Torres (2013), a limitação da liberdade de expressão é coesa para justificar a coexistência de direitos incompatíveis.

\section{CONSIDERAÇÕES FINAIS}

O presente artigo visou demonstrar como o discurso de ódio está inserido na sociedade brasileira e é disseminado principalmente no ambiente da internet, pela facilidade e pelo anonimato com que esta pode ser utilizada. Depois de exposto o embate entre o discurso de ódio e a liberdade de expressão e como isso recai sobre a dignidade humana, ficou evidenciada relação entre ele e a violência, sendo que, além de ser um causador imediato dela, é um propulsor de manifestações maiores de violência.

Na busca pela liberdade de expressão plena, constata-se efetivamente que a educação sempre é tida como a principal motriz para a redução do problema. Ela é capaz de moldar a sociedade, é uma maneira de, em médio e em longo prazo, reduzir as desigualdades. No entanto faz-se necessário 
incentivar o recurso a ela e à busca de informações de qualidade, para se evitar a desinformação que pode se aliar ao preconceito, causadores das chamas do discurso de ódio.

Nesse sentido, a liberdade de expressão, que é o pilar da democracia, fica fragilizada, e a disparidade de opiniões pode criar conflitos que não têm soluções. A mídia, por sua vez, aparece em um compilado entre informação imprescindíveis contra o sensacionalismo e as fake news, o que desencadeia mais suplementos à violência. O intuito deve ser sempre buscar uma equidade básica para melhorar a democracia. Daí se aponta o fato de o direito de resposta ser aludido e dar voz aos principais interessados, isto é, às minorias sociais, e ouvi-las.

Conclui-se que o ódio precisa ser combatido e criminalizado. Ele vai continuar a ser parte da sociedade, por sofrer mutações, mas é essencial que seja combatido pela educação e pela informação em vista da harmonia social, da preservação da democracia e da eliminação do conflito entre a liberdade de expressão e a dignidade humana. É necessário debatê-lo, repudiá-lo e gerar uma conjuntura individual, coletiva e jurídica mais sensível nas relações humanas.

\section{REFERÊNCIAS}

ADAMS, Ian; DYSON, R. W. Cinquenta pensadores políticos essenciais: da Grécia antiga aos dias atuais. Tradução de Mario Pontes. Rio de Janeiro: DIFEL, 2006.

AGENCIA SENADO. CPI é prorrogada por 180 dias e investigará Fake News sobre coronavírus. Disponível em: https://www12.senado.leg.br/noticias/ materias/2020/04/03/cpi-e-prorrogada-por-180-dias-e-investigara-fake-newssobre-coronavirus Acesso em: 19 abr. 2020.

ARENDT, Hannah. Eichmann em Jerusalém: um relato sobre a banalidade do mal. Tradução de José Rubens Siqueira. São Paulo: Companhia das Letras, 1999.

BERALDO, Paulo. Discurso de ódio surge em fissuras da democracia. O Estado de São Paulo, São Paulo, 6 de novembro, 2019. Disponível em: https://politica. estadao.com.br/noticias/geral,discurso-de-odio-surge-em-fissuras-da-democraciadiz-pesquisadora,70003078090. Acesso em: 15 jan. 2020. 
O discurso de ódio e a liberdade de expressão: seu feito sobre a dignidade humana e apotencialização da violência

BRASIL. Tribunal Regional Federal. Apelação Criminal n. 5005254-26.2015.4.04.7005. Apelante: Cesar Luís Sottiili Junior. Relator: Desembargadora Federal Claudia Cristina Cristofani. Porto Alegre, 13 de dezembro de 2018. Disponível em: https://trf-4.jusbrasil.com.br/jurisprudencia/658790654/apelacao-criminalacr-50052542620154047005-pr-5005254-2620154047005/inteiro-teor658790685?ref=juris-tabs Acesso em: 15 maio 2020.

BRASIL. Projeto de Lei n. 473. Altera o Decreto-Lei n. 2.848, de 7 de dezembro de 1940 - Código Penal, para tipificar o crime de divulgação de notícia falsa. BrasíliaDF: Senado Federal, 2017. Disponível em: https://www25.senado.leg.br/web/ atividade/materias/-/materia/131758. Acesso em: 2 jun. 2020.

BRASIL. Senado Federal. Projeto de Lei n. 80. Dispõe sobre a prática de crime de discriminação ou preconceito de raça, cor, etnia, religião ou procedência nacional por intermédio da rede Internet ou de outras redes de computadores de acesso público. Brasília-DF: Senado Federal, 2016. Disponível em: https://www25.senado. leg.br/web/atividade/materias/-/materia/125088. Acesso em: 2 jun. 2020.

BRASIL. Supremo Tribunal Federal. Habeas Corpus n. 134.682. Paciente. Jonas Abib. Relator: Ministro Edson Fachin. Rio de Janeiro, 29 de novembro de 2016. Disponível em: http://redir.stf.jus.br/paginadorpub/paginador. jsp?docTP=TP\&doclD=13465125. Acesso em: 15 maio 2020.

BRASIL. Lei n. 7.716, de 5 de janeiro de 1989. Dispõe sobre crimes de preconceito de raça ou de cor. Brasília-DF, 1989. Disponível em: http://www.planalto.gov.br/ ccivil_03/leis/l7716.htm Acesso em: 20 maio 2019.

BRASIL. Constituição da República Federativa do Brasil. Brasília-DF, 1988. Disponível em: http://www.planalto.gov.br/ccivil_03/constituicao/constituicao.htm. Acesso em: 18 maio 2020.

BRUGGER, Winfried. Proibição ou proteção do discurso de ódio? Algumas observações sobre o Direito Alemão e o Americano. Revista Direito Público, v. 15, p. 117-63, 2007. Disponível em: https://www.portaldeperiodicos.idp.edu.br/ direitopublico/article/view/1418/884\&gt. Acesso em: 4 mar. 2020.

CARNEIRO, Maria Luiza Tucci. Por uma cultura de tolerância. Revista Webmosaica do Instituto Cultural Judaico, 2011.

CERQUEIRA, Daniel. et al. Atlas da Violência-2019. Rio de Janeiro: IPEA/FBSP, 2019. Disponível em: https://www.ipea.gov.br/portal/images/stories/PDFs/relatorio_ institucional/190605_atlas_da_violencia_2019.pdf. Acesso em: 11 maio 2020. 
CONSELHO NACIONAL DO MINISTÉRIO PÚBLICO. De 25\% a 80\% dos homicídios no Brasil são cometidos por impulso ou motivo fútil. CNMP, Brasília-DF, 2012. Disponível em: https://www.cnmp.mp.br/portal/institucional/3-noticias/todasas-noticias/1699-conte-ate-10413. Acesso em: 20 maio 2020.

COSTA, Fabrício Veiga; FREITAS, Andrade Érica Patrícia Moreira. A linha tênue entre o exercício do direito de liberdade religiosa em face do discurso de ódio. Prisma Jurídico, São Paulo, v. 16, n. 2, p. 479-503, 2017.

COSTA, Regina Elis Carvalho. O bêbado e a equilibrista. Compositor: João Bosco e Aldir Blanc. Brasil: Warner Music, 1979.

D'ALESSANDRO, Marcela Duarte; COSTA, Jales Dantas. Direito de resposta no jornalismo: instrumento de cidadania e democracia. Estudos em Jornalismo e Mídia, [s.I.], v. 16, n. 2, p. 131-43, 2019. Disponível em: DOI: http://dx.doi. org/10.5007/1984-6924.2019v16n2p131

HORVAT, Srećko. Mais contagioso é o medo. El País, 2020. Disponível em: https:// brasil.elpais.com/internacional/2020-02-16/mais-contagioso-e-o-medo.html. Acesso em: 11 maio 2020.

KARNAL, Leandro. Todos contra todos: o ódio nosso de cada dia. Rio de Janeiro: LeYa, 2017.

MARQUES, Heitor Romero; MANFROI, José; CASTILHO, Maria Augusta; NOAL, Mirian Lange. Metodologia da pesquisa e do trabalho científico. 5. ed. rev. e atual. Campo Grande: UCDB, 2017.

MEYER-PFLUG, Samantha Ribeiro. O discurso do ódio por ocasião dos trinta anos da Constituição Federal. Universidade de Fortaleza, 2018. Disponível em: https:// www.youtube.com/watch?v=bjsfoForm6o. Acesso em: 25 mar. 2020.

MILL, John Stuart. Sobre a liberdade. 2. ed. Petrópolis: Editora: Vozes, 1991.

O QUE É discurso de ódio. SaferLab, [s.I.], [s.d.].Disponível em: http://saferlab.org. br/o-que-e-discurso-de-odio/. Acesso em: 24 maio 2019.

OLIVA, Anderson Ribeiro. Os africanos entre representações: viagens reveladoras, olhares imprecisos e a invenção da África no imaginário Ocidental. Em Tempo de Histórias, n. 9, p. 90-114, 2005. 
O discurso de ódio e a liberdade de expressão: seu feito sobre a dignidade humana e apotencialização da violência

ONU alerta para um "tsunami de ódio e xenofobia". Portal G1, Secretário-Geral da ONU, 2020. Disponível em: https://g1.globo.com/mundo/noticia/2020/05/08/ onu-alerta-para-tsunami-de-odio-e-xenofobia.ghtml/. Acesso em: 20 maio 2020.

ONU NEWS. Temos de lembrar que crimes de ódio são precedidos por discurso de ódio. Portal da ONU, 28 jun. 2019. Disponível em: https://news.un.org/pt/ story/2019/06/1678221 Acesso em: 22 mar. 2020.

ROUSSEAU, Jean-Jacques. Discurso sobre a origem e os fundamentos da desigualdade entre os homens. São Paulo: Martin Claret, 2005.

SAFADI, Marco Aurelio Palazzi. Novo coronavírus (COVID-19). Sociedade Brasileira de Pediatria, São Paulo, 14 fev. 2020. Disponível em: https://www.sbp.com.br/ fileadmin/user_upload/22340d-DocCientifico-Novo_coronavirus.pdf Acesso em: 13 maio 2020.

SANTOS, Boaventura Sousa. Reconhecer para libertar: os caminhos do cosmopolitismo multicultural. Rio de Janeiro: Civilização Brasileira, 2003.

SILVA, José Afonso da. Curso de Direito Constitucional Positivo. 25. ed. São Paulo: Malheiros, 2005.

TÔRRES, Fernanda Carolina. O direito fundamental à liberdade de expressão e sua extensão. Revista de Informação Legislativa, Brasília-DF, Senado Federal, ano 50, n. 200, out./dez. 2013. Disponível em: https://www2.senado.leg.br/bdsf/bitstream/ handle/id/502937/000991769.pdf?sequence=1. Acesso em: 30 maio 2020. 
